\title{
ON THE JOINT INTERPRETATION OF TOTAL GAS CONTENTS AND STABLE ISOTOPE RATIOS IN ICE CORES
}

\author{
by
}

\author{
D. Jenssen
}

(Meteorology Department, University of Melbourne, Parkville, Victoria 3052, Australia)

\author{
and U. Radok
}

(Cooperative Institute for Research in Environmental Sciences, University of Colorado, Box 449,

Boulder, Colorado 80309, U.S.A.)

ABSTRACT

Total gas contents of ice cores together with temperature estimates derived from $180 / 160$ and ${ }^{2} \mathrm{D} /{ }^{1} \mathrm{H}$ values have been used to separate topographic and climatic changes in the deposition temperature history of the ice (Raynaud 1977, Jenssen 1978). The most recent analysis (Jenssen in press) made use of two linear relationships (one purely empirical, the other established empirically but subsequently justified theoretically) to derive an algebraic expression for the change of surface temperature with ice-sheet elevation. A physical line of reasoning is presented which instead infers the climatic history from changes in the surface topography of the ice sheet. This suggests that a complete interpretation of core data must go hand in hand with ice-sheet modeling.

\section{INTRODUCTION}

The use of ice-core isotopes as proxy climatic indicators acquired a new level of sophistication when it was realized by Raynaud and Lorius (1973) that the total gas content of the ice in a core section provides a measure of the elevation at which the ice in question was created by pore close-off. Data from both Antarctica and Greenland established two linear relationships: between the close-off pore volume $V_{C}$ and the ice temperature $T$ at the level and time of close-off, and between total gas content $v$ and the elevation of the ice at close-off $E$. The first of these relationships represents a material property which could be independent of time, location, and climatic conditions; the physical processes involved have been discussed by Raynaud (in press). The second linear relationship was shown by Jenssen (in press) to be well approximated, for the relevant range of surface temperatures and inversion features, by the theoretical $\mathrm{V}-\mathrm{E}$ dependence in a constant-1apse rate ("polytropic") atmosphere. This implies that both the theoretical and empirical regression coefficients could be climate-dependent. Jenssen obtained an algebraic expression for the crucial T-E dependence from the linear approximation to the strict theoretical $V-E$ relationship, valid on the average over the height and temperature ranges in question.

A different approach to the problem is taken in this paper. It starts from a relationship for the change along a sloping ice-sheet surface in the surface pressure below a temperature inversion.
After demonstrating that this again leads to an approximately linear $V-E$ dependence, the height difference between the close-off levels of two core sections is estimated and used to define a "topographical" temperature lapse rate (rate of surface temperature change along the ice-sheet surface). The climatic temperature change $\Delta T_{c l}$ that is contained in the total (isotope-derived) temperature change $\Delta T$ since the core section was formed is then obtained from the difference between the indicated topographical lapse rate $\Delta T / \Delta \mathrm{E}$ and the true lapse rate $\lambda$ valid at the time of the ice deposition. Values of $\lambda$ are deduced from the surface energy balance and the katabatic winds of the present ice sheet and of model simulations of past ice-sheet configurations and their atmospheric boundary layers.

THEORY

1. The hydrostatic equation for pressure changes along an ice-sheet surface

We assume a surface inversison of (10cally) constant thickness $H$ and lapse rate $\gamma_{i}=\left(T_{T}-T_{1}\right) H$, cf. Figure 1. The surface pressure $p_{1}$ is related to

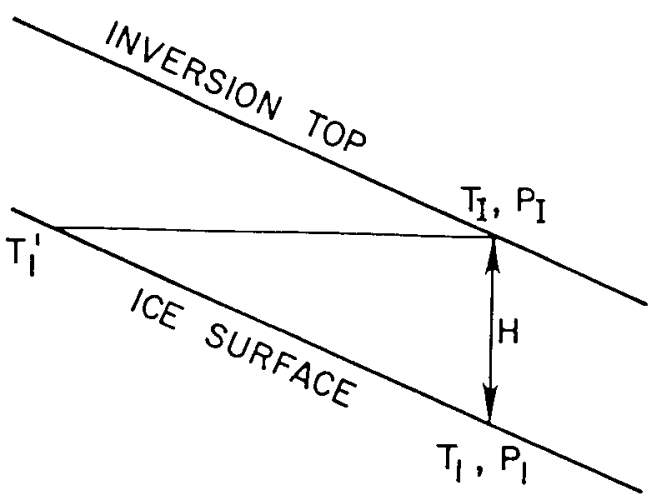

Fig.1. Notation used in the paper. 
that above the inversion by

$$
p_{1}=p_{I}\left(1-H_{i} / T_{1}\right)^{-g / \gamma_{i} R} \text {. }
$$

Differentiation with respect to $E$, and substitution of the free-atmosphere hydrostatic equation

$$
\frac{\partial p_{I}}{\partial E}=-\frac{g p_{I}}{R T_{I}}
$$

and of the first two terms of the power series for the second right hand factor gives

$$
\frac{\partial p_{1}}{\partial E}=-\frac{p_{1} g}{R T_{1}} \frac{T_{1}^{\prime}}{T_{I}}=-\frac{p_{1}}{R} \frac{g r}{T_{1}}
$$

with $r=T_{1}^{\prime} / T_{I}$, cf. Figure 1 . This factor remains close to the value 0.96 over the distances here considered. A comparison of (3) with (2) shows that the pressure falls more slowly with elevation along the ice-sheet surface than along the vertical in the free atmosphere. This gives rise to a weak "glacial anticyclone" over large ice sheets (Radok 1981). 2. The theoretical relationship between total gas content $V$ and elevation $E$

The total gas content is given by

$$
v=v_{c_{1}} \frac{T_{0}}{T_{1}} \frac{p_{1}}{p_{0}}
$$

where $V_{c_{1}}$ is the pore volume at close-off and the

subscript o refers to a reference state (sea-level or the present conditions at the top of the core). With Raynaud and Lebel's (1979) regression equation

$v_{c}=c T+d$ and a quasi-constant harmonic mean temperature defined by

$$
(\tilde{1 / T})=\left(1 /\left(T_{2}-T_{1}\right)\right) \int_{T_{1}}^{T_{2}} d T / T
$$

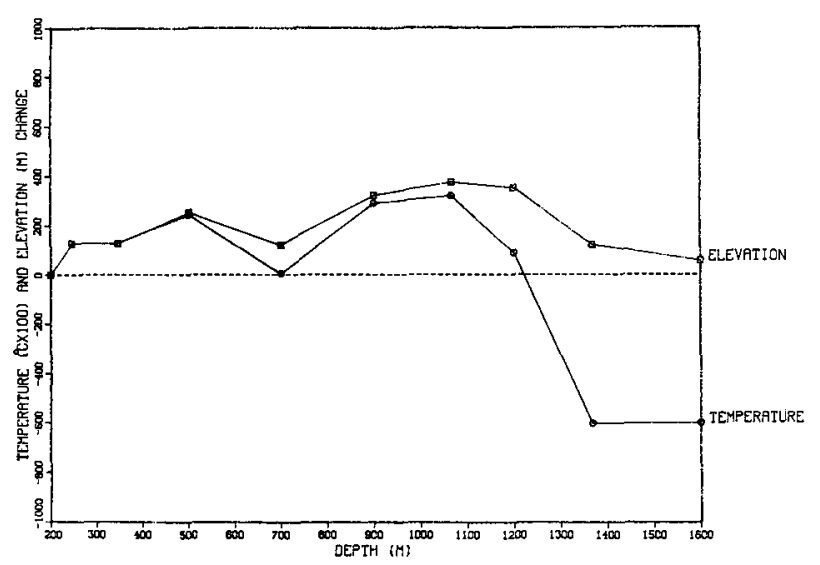

Fig.2. Estimated changes in deposition temperature and elevation for a $1400 \mathrm{~m}$ section of the Byrd core. Numerical values are given in Table I; the input gas contents and temperatures ( $\delta$ values) have been taken without adjustment from Raynaud (1977, table VII). The ordinate scale represents meters (elevation) and ${ }^{\circ} \mathrm{C} \times 100$ (temperature). and with $T_{2}=203 \mathrm{~K}, T_{1}=273 \mathrm{~K}$ in the power series approximation for $\mathrm{p}_{1} / \mathrm{p}_{0}$, this becomes

$$
v=T_{0}(c+d(1 / T)[1-(g / R)(1 / T) r E]) \text {, }
$$

or numerically $V=0.1352-1.704 \times 10^{-5} \mathrm{E}$. Raynaud and Lebel's (1979) result was $V=0.138-1.66 \times 10^{-5} \mathrm{E}$. 3. Estimation of height and temperature changes

Integration of (3) over the height/time interval separating two neighboring core sections, substitution in (4), and solving for the height difference leads to

$$
\Delta E=\frac{R T_{I}}{g T_{1}}\left(\frac{T_{j}+T_{j+1}}{2}\right) \text { en }\left[\frac{V_{j}}{V_{j+1}} \frac{\left(V_{c}\right)_{j+1}}{\left(V_{c}\right)_{j}} \frac{T_{j}}{T_{j+1}}\right] \text {, }
$$

where the subscripts refer to the $j$ th or $(j+1)$ th datum points in the core. Now $T_{I} / T^{\prime} \gg T / T^{\prime} \simeq 1$, and $V_{c}=c T+d$ (Raynaud and Lebel 1979); furthermore, the inversion temperature $T_{I}$ has been found to be a linear function of the ice-sheet surface temperature both for Antarctica (Phillpot and Zillman 1970) and for Greenland (Putnins 1970, table XXXIX). Thus, $\Delta E$ is fully determined by the total gas contents of the two sections and by the temperatures deduced from their isotope ratios. The computed height difference arises from the fact that the ice in the two core sections has come from different locations; moreover, the shape of the ice sheet may also have changed between the formation dates of the ice in the two sections. For a proper interpretation of the core record, these "advective" and "topographical" effects need to be separated.

A corresponding problem arises in connection with the temperatures in Equation (7). During the time interval separating the sections, the surface temperature at the level of section 1 may have undergone a climatic change $\Delta T_{C l}$. A "topographical lapse rate" between two points $A$ and $B$ may be defined as

$$
\lambda=\left(T_{A}-T_{B}\right) / \Delta E \text {. }
$$

Now, if $T_{B}=T_{j+1}$, then we may write $T_{B}=T_{j+1}+\Delta T_{c l}$, where $\Delta T_{C l}$ is the climatic change over the time it takes the ice at location $B$ to move to location $A$ downstream. Hence,

$$
\lambda=\left[T_{j}-\left(T_{j+1}+\Delta T_{C l}\right)\right] / \Delta E .
$$

Defining $\lambda^{\prime}=\left(T_{j}-T_{j+1}\right) / \Delta E$, then clearly

$$
\Delta T_{c l}=\left(\lambda^{\prime}-\lambda\right) \Delta E
$$

Note that, strictly, the $\Delta \mathrm{E}$ terms in Equations (8a) and (8b) are slightly different because the icesurface shape will, in general, change with time. However, over the time interval separating two adjacent core sections, this is a minor effect; a strict justification for neglecting it will be given in a separate paper applying the model presented here to a modeled ice-sheet history. Also, it will be shown that $\Delta T_{C l}$ is the true climate change, and contains no effects due to motion down the flow line or thickening/thinning of the ice.

The key parameter in Equation (9) is the topographical lapse rate $\lambda$ which prevailed during the time interval over the ice-sheet region under consideration. The estimation of this parameter forms a further problem to be solved for an adequate interpretation of a core record.

\section{DISCUSSION}

The separation of advective and topographical contributions to $\Delta \mathrm{E}$ can be made, in principle, by a model reconstruction of the ice-sheet shape that existed during the time interval between the formation of the two core sections. While the surface slope for a single interval will be subject to con- 
TABLE I. SAMPLE CALCULATION FOR THE BYRO CORE

\begin{tabular}{|c|c|c|c|c|c|c|c|c|c|}
\hline $\begin{array}{l}\text { Depth } \\
\text { (m) }\end{array}$ & $\begin{array}{c}\text { Total gas } \\
\text { content } \\
\text { ( } \mathrm{mm}^{3} \mathrm{~g}^{-1} \text { ice) }\end{array}$ & $\begin{array}{c}\delta^{180 / 160} \\
(0 / 00)\end{array}$ & $\begin{array}{l}\mathrm{Ti} \\
(\mathrm{K})\end{array}$ & $\begin{array}{l}\Delta E \\
(m)\end{array}$ & $\begin{array}{c}\lambda^{\prime} \\
\left({ }^{\circ} \mathrm{C} / 100 \mathrm{~m}\right)\end{array}$ & $\begin{array}{c}\lambda \\
\left({ }^{\circ} \mathrm{C} \quad 100 / \mathrm{m}\right)\end{array}$ & $\begin{array}{l}\Delta \mathrm{T} C l \\
\left({ }^{\circ} \mathrm{C}\right)\end{array}$ & $\begin{array}{l}\sum \Delta E \\
(m)\end{array}$ & $\begin{array}{c}\left.-\sum \Delta T_{C l} c\right] \\
\left({ }^{\circ} \mathrm{C}\right)\end{array}$ \\
\hline 180.4 & 119 & -32.9 & 244.7 & & & & 100 & 0 & 0 \\
\hline 247.0 & 117 & -32.9 & 244.7 & 128.1 & 0 & 1 & -1.28 & 128 & 1.3 \\
\hline 347.3 & 117 & -32.9 & 244.7 & 1262 & 070 & 1 & 16 & 128 & 1.3 \\
\hline 501.3 & 115 & -33.1 & 244.6 & 120.3 & 0.079 & 1 & -1.16 & 254 & 2.4 \\
\hline 701.0 & 117 & -33.9 & 244.8 & 202.3 & -0.198 & 1 & -2.42 & 120 & 0.1 \\
\hline 900.7 & 114 & -33.3 & 244.4 & 55.6 & 1.439 & 2 & -0.31 & 322 & 2.9 \\
\hline 1066.8 & 113 & -34.35 & 243.6 & -26.6 & -6.767 & 2 & 2.33 & 378 & 3.2 \\
\hline 1200.44 & 113 & -36.8 & 241.8 & -180.5 & -1.828 & 2 & 6.91 & 351 & 0.9 \\
\hline 1367.5 & 115 & $\begin{array}{l}-41.25 \\
-40.34\end{array}$ & 238.5 & -113.9 & 0.527 & 0.5 & -0.03 & $\begin{array}{r}121 \\
57\end{array}$ & $\begin{array}{l}-6.0 \\
-6.0\end{array}$ \\
\hline
\end{tabular}

siderable uncertainty, the joint analysis of the $\Delta E$ values for an entire intermediate or deep core, and even more for several cores from different locations in the same ice drainage basin, can be expected to produce a closely constrained set of values for $\Delta E$ and $\Delta T_{C l}$.

To estimate the true topographical lapse rate $\lambda$, we can take recourse to the fact that this parameter is governed by the energy balance of the sloping icesheet surface which drives its katabatic wind system. Budd and others (1971, figs. 3 and 4 ) have shown that four different regions must be distinguished in this context. Over the central plateau of Antarctica, $\lambda$ is relatively small and variable, ranging from $0.5^{\circ} / 100 \mathrm{~m}$ to pockets of small positive values (i.e. temperature increase with elevation). The central region (which is of very restricted extent for west Antarctica and Greenland) is surrounded by a belt with $\lambda$ values exceeding $2 \% / 100 \mathrm{~m}$. This is the source region of the katabatic winds which further downslope create the third zone, with $\lambda$ close to the dryadiabatic lapse rate of $1^{\circ} 100 \mathrm{~m}^{-1}$. Beyond it lies the steeply-sloping coastal belt with smaller $\lambda$ values, created probably by the evaporation of drift snow which provides the additional forcing of the extremely strong winds in that region (Radok $1973)$.

This distribution of $\lambda$ values can be expected to hold for any ice-sheet configuration, but the extent of the different zones and their boundaries would change with the ice-sheet topography. A sequence of model-simulated ice-sheet shapes, providing a plausible and consistent separation of advective and topographical contributions to a complete set of $\Delta E$ values, should at the same time account for the changes in $\lambda$, thereby suggesting a plausible and consistent series of climatic temperature changes. This constitutes what might be called the "grand problem" of ice-core climatology.

\section{SAMPLE RESULTS}

The procedures described above have not yet been fully tested; they will merely be illustrated by a calculation for the Byrd core using the gas-content and temperature $S$ data in table VII of Raynaud (1977). The depth range covered is from 180.4 to $1601.9 \mathrm{~m}$ and corresponds to a time interval of about $13 \mathrm{ka}$. Balance model results for the Byrd flow line (Budd and others 1971: profiles 1 (top)) suggest that the ice at the lower level comes from $200 \mathrm{~km}$ upstream and from about $300 \mathrm{~m}$ above the formation level of the ice now at $180 \mathrm{~m}$ depth. Present topographical lapse rates (Budd and others 1971: map 3/4) lie around $1 \% / 100 \mathrm{~m}$ in the katabatic winds around Byrd but rise to above $2 \% / 100 \mathrm{~m}$ in the source region of the deeper ice. This is the justification for the $\lambda$ values used in the calculations. The results are shown in Table I and Figure 2; they resemble the corresponding estimates obtained by Raynaud (1977) and Jenssen (in press). It can be seen from Equations (8) and (9) that the estimated climatic temperature changes are highly sensitive to errors in $\Delta \mathrm{E}$. This underlines the need for using data from several cores for a consistent climatic and topographical ice-sheet history.

Finally, given a sequence of topographical lapse rates defined by a model history of an ice sheet, a succession of temperature fields for the ice-sheet surface is directly determined by the temperatures along the ice-sheet boundary (which can be inferred from other proxy data or from a climate model). The calculations of this paper can, in that case, be done without invoking the isotope/temperature relationship, which thereby is itself opened to study as a historical phenomenon.

\section{REFERENCES}

Budd WF, Jenssen D, Radok U 1971 Derived physical characteristics of the Antarctic ice sheet. ANARE Interim Reports Ser A(IV) Glaciology (Publication 120)

Jenssen D 1978 Climatic and topographic changes from glaciological data, In Pittock A B ard others (eds) climatic change and variability: a southem perspective. Cambridge, Cambridge University Press: 77-81

Jenssen $D$ In press. Elevation and climatic change from total gas content and isotope measurements. In Robin $G$ de $Q$ (ed) The climatic record in poiar ice sheets. Cambridge, Cambridge University Press

Phillpot H R, Zillman J $W 1970$ The surface temperature inversion over the Antarctic continent. Joumal of Geophysical Research 75(21): 4161-4169

Putnins P 1970 The climate of Greenland. In Orvig $\mathrm{S}$ (ed) climate of the polar regions. Amsterdam etc, Elsevier: 3-128

Radok U 1973 On the energetics of surface winds over the Antarctic ice cap. In 0rvig S (ed) Energy fluxes over polar surfaces. Froceedings of the IAMAP/IAPSO/SCAR/WMO Sumposizum, Moscow... 1971: 69-100 (WMO Technical Note 129) 
Radok U 1981 The lower atmosphere of the polar regions. Geologische Rundschau 70: 703-724

Raynaud D 1977 Les inclusions gazeuses dans la glace de glacier; leur utilisation comme indicateur du site de formation de la glace polaire; applications climatiques et rheologiques. Publication du Laboratoire de Glaciologie du Centre National de la Recherche Scientifique 214

Raynaud D In press. Total gas content. In Robin $G$ de $Q$ (ed) The climatic record in polar ice sheets. Cambridge, Cambridge University Press Raynaud D, Lebel B 1979 Total gas content and surface elevation of polar ice sheets. Nature 281(5729): 289-291

Raynaud D, Lorius C 1973 Climatic implications of total gas content in ice at Camp Century. Nature $243(5405): 283-284$ 